\title{
GENERALIZATIONS OF REGULAR AND NORMAL SPACES II
}

\author{
AHMAD AL-OMARI and TAKASHI NOIRI
}

\begin{abstract}
A family $m_{X}$ of subsets of a nonempty set $X$ is called an $m$-structure [17]. A set $X$ with a topology $\tau$ and $m$-structure $m_{X}$ is called a mixed-space and is denoted by $\left(X, \tau, m_{X}\right)$. As a generalization of $g$-closed sets due to Levine [10], we introduce the notion of $m_{g}$-closed sets in $\left(X, \tau, m_{X}\right)$. By using $m_{g}$-open sets, we define and investigate mixed-regularity and mixed-normality in $\left(X, \tau, m_{X}\right)$. As special cases, we obtain $\mathcal{I}_{g}$-regular spaces [13] and $s$-normal spaces [8].
\end{abstract}

MSC 2010. 54A05, 54C08, 54C10, 54D15.

Key words. Minimal structure, $m_{g}$-closed set, mixed-space, mixed-regular, mixednormal.

\section{REFERENCES}

[1] A. Al-Omari and T. Noiri, On operators in ideal minimal spaces, Mathematica, 58 (81) (2016), 3-13.

[2] A. Al-Omari and H. Al-saadi, A topology via $\omega$-local functions in ideal spaces, Mathematica, 60 (83) (2018), 103-110.

[3] A. Al-Omari and T. Noiri, Generalizations of regular and normal spaces, Annales Univ. Sci. Budapest., 61 (2018), 121-135.

[4] A. Al-Omari and T. Noiri, Operators in minimal spaces with hereditary classes, Mathematica, 61 (84) (2019), 101-110.

[5] A. Al-Omari, H. Al-saadi and T. Noiri, On extremally disconnected spaces via mstructures, Commun. Korean Math. Soc., 34 (2019), 351-359.

[6] H. Al-Saadi and A. Al-Omari, Some operators in ideal topological spaces, Missouri J. Math. Sci., 30 (2018), 59-71.

[7] H. Al-saadi, A. Al-Omari and T. Noiri, On hyperconnected spaces via m-structures, Ital. J. Pure Appl. Math., 42, (2019), 290-300.

[8] S.P. Arya and T.M. Nour, Characterizations of s-normal spaces, Indian J. Pure Appl. Math., 21 (1990), 717-719.

[9] N. Levine, Semi-open sets and semi-continuity in topological spaces, Amer. Math. Monthly, 70 (1963), 36-41.

[10] N. Levine, Generalized closed sets in topology, Rend. Circ. Mat. Palermo (2), 19 (1970), $89-96$.

[11] S.N. Maheshwari and R. Prasad, On s-normal spaces, Bull. Math. Soc. Sci. Math. R. S. Roumanie, 20(70) (1978), 27-29.

[12] H. Maki, K.C. Rao and A. Nagoor Gani, On generalizing semi-open and preopen sets, Pure Appl. Math. Sci., 49 (1999), 17-29.

The authors thank the referee for his helpful comments and suggestions.

DOI: $10.24193 /$ mathcluj.2021.1.01 
[13] M. Navaneethakrishnan, J. Paulraj Joseph and D. Sivaraj, $I_{g}$-normal and $I_{g}$-regular spaces, Acta Math. Hungar., 125 (2009), 327-340.

[14] T. Noiri, Almost $\alpha$ g-closed functions and separation axioms, Acta Math. Hungar., 82 (1999), 193-205.

[15] T. Noiri, A unified theory for modifications of $g$-closed sets, Rend. Circ. Mat. Palermo (2), 56 (2007), 171-184.

[16] T. Noiri, A unified theory for certain modifications of generalized closed sets, Int. J. Gen. Top., 1 (2008), 87-99.

[17] V. Popa and T. Noiri, On M-continuous functions, An. Univ. "Dunărea de Jos" Galaţi, Ser. Mat. Fiz. Mec. Teor. (2), 43 (23) (2000), 31-41.

[18] J. Sanabria, E. Rosas, C. Carpintero and M. Salas-Brown, On the further unified theory of ideal generalized closed sets, J. Adv. Math. Stud., 4 (2011), 83-96.

Received September 23, 2019

Accepted May 22, 2020

\author{
Al al-Bayt University \\ Faculty of Sciences \\ Department of Mathematics \\ P.O. Box 130095, Mafraq 25113, Jordan \\ E-mail: omarimutah1@yahoo.com \\ https://orcid.org/0000-0002-6696-1301 \\ 2949-1 Shiokita-cho \\ Hinagu, Yatsushiro-shi, Kumamoto-ken \\ 869-5142 Japan \\ E-mail: t.noiri@nifty.com \\ https://orcid.org/0000-0002-0862-5297
}

